\title{
PENERAPAN METODE SEO ON PAGE DAN OFF PAGE PADA WEB PENJUALAN ONLINE UNTUK MENINGKATKAN RANKING SERP
}

\author{
Yoga Dwitya Pramudita ${ }^{1)}$, Huzaini $^{2)}$, Firdaus Solihin ${ }^{3)}$ \\ 1), 2),3) Program Studi Teknik Informatika, Fakultas Teknik, Universitas Trunojoyo \\ Jl Raya Telang, PO. BOX 2, Kamal, Bangkalan \\ Email :yoga@trunojoyo.ac.id ${ }^{1)}$,zen96ev@ gmail.com ${ }^{2}$
}

\begin{abstract}
Abstrak
Search Engine Optimization (SEO) merupakan serangkaian proses yang dilakukan secara sistematis dalam sebuah website untuk meningkatkan lalu lintas kunjungan organik melalui mesin pencari. SEO perlu diterapkan pada website dengan tujuan bisa dikenali oleh mesin pencari. Diketahui terdapat salah satu Usaha Kecil Menengah (UKM) di Madura yang sudah memanfaatkan website dalam memasarkan produknya. Namun website yang dibangun tidak dapat dikenali oleh mesin pencari dan tidak dapat berada pada halaman pertama pada Search Engine Result Page (SERP). Agar website dapat dikenali oleh mesin pencari dan muncul di halaman awal pencarian maka solusi yang ditawarkan yaitu dengan menerapkan metode SEO. Metode ini akan diterapkan dan diuji tingkat keefektifitasannya pada situs penjualan online UKM Madura. Dari hasil pengujian website yang telah menerapkan metode SEO, pengguna baru, sesi dan lalu lintas organik yang didapat, ternyata mengalami peningkatan jika dibandingkan dengan pengujian sebelumnya yang tanpa menerapkan metode ini (peningkatan mencapai 600\% untuk pengguna baru, $210,42 \%$ untuk sesi dan 46,31\% untuk pencarian organik). Dan jika dilihat dari posisi SERP terdapat peningkatan yang pesat dengan rata-rata kemunculan website berada pada halaman 1 jika dibandingkan dengan pengujian website tanpa menggunakan metode SEO yang rata-rata kemunculan website berada pada rank 5 untuk kata kunci "UKM Madura". Hal ini menunjukkan bahwa metode SEO dapat meningkatkan popularitas suatu website jika diterapkan dengan benar.
\end{abstract}

Kata kunci: SEO, Website, Pemasaran UKM.

\begin{abstract}
Search Engine Optimization (SEO) is a series of processes that are carried out systematically on a website to increase organic traffic through search engines. SEO needs to be applied to websites with the aim of being recognized by search engines. It is known that there is one Usaha Kecil Menengah (UKM) in Madura that has used website to market its products. But the website that is built cannot be recognized by search engine and cannot be on first page of Search Engine Result Page (SERP). In order to the website can be recognized by search engines and appear on the initial search page, the solution offered is by applying the SEO method. This method will be applied and tested the level of effectiveness on the Madura SME online sales site. From the testing results websites that have implemented SEO methods, new users, sessions and organic traffic obtained, it has increased compared to previous tests without applying this method (up to $600 \%$ for new users, $210.42 \%$ for sessions and $46.31 \%$ for organic search). And when viewed from the SERP position there is a rapid increase with average appearance of website on page 1 when compared to testing websites without using SEO methods, the average website appearance is in rank 5 for the keyword "UKM Madura". This shows that SEO methods can increase popularity of a website if applied correctly.
\end{abstract}

Keywords : SEO, Website, SME Marketing.

\section{PENDAHULUAN}

Website penjualan online telah menjadi sebuah media bagi masyarakat modern dalam proses jual beli. Penggunaan website sangat penting dalam meningkatkan nilai produksi. Selain itu dengan memanfaatkan website penjualan online dalam operasional bisnis, Usaha Kecil Menengah (UKM) akan mendapatkan akses pasar yang lebih luas dan berpeluang mendapatkan pelanggan baru [1]. Situs ukm.madura.web.id merupakan sebuah situs penjualan online yang dikembangkan untuk membantu para pemilik UKM di pulau Madura dalam menawarkan produknya. Saat ini sebagian besar UKM belum memiliki Sumber Daya Manusia (SDM) yang cukup untuk pengembangan bisnis menggunakan website dalam menawarkan produknya serta mendapatkan konsumen melalui kunjungan website. Bahkan ada 
beberapa UKM yang telah menerapkan sistem pemasaran melalui website terhenti karena terkendala dengan pengetahuan yang terbatas dalam pengelolaan web. Mengembangkan website penjualan online membutuhkan pengetahuan khusus agar website dapat mudah dikenali oleh mesin pencari, sehingga dapat menduduki posisi pertama Search Engine Result Page (SERP).

Ketika website penjualan online menempati posisi teratas SERP maka peluang untuk dikunjungi meningkat, sehingga peluang terjadinya transaksi juga besar. Solusi untuk memudahkan suatu situs dapat dikenali oleh mesin pencari yaitu dengan menerapkan metode SEO pada website yang dikelola. SEO merupakan serangkaian proses yang dilakukan secara sistematis yang bertujuan untuk meningkatkan jumlah dan kualitas trafik kunjungan melalui mesin pencari menuju situs tertentu dengan memanfaatkan mekanisme kerja atau algoritma mesin pencari tersebut [2]. SEO melibatkan sekumpulan dari teknik-teknik tertentu baik on page dan off page dengan tujuan dapat meningkatkan peringkat di mesin pencari [3]. Penerapan metode SEO on page dilakukan di kode html dimana beberapa teknik yang dapat dilakukan yaitu dengan cara mengoptimasi kata kunci website, struktur web, isi konten dan gambar. Selain itu juga optimasi di sitemap, link dan robot.txt, dll., yang mana kode-kode tersebut akan dibaca oleh bot ketika melakukan proses crawling untuk proses indexing. Sedangkan Off page berkonsentrasi pada pembuatan backlink, directory submission juga social media bookmarking [4]. Penerapan SEO on page yang telah dilakukan dalam penelitian terdahulu mendapatkan hasil yang baik. Dalam waktu empat bulan, pengunjung unik sudah mencapai 87-190 pengunjung per hari [5]. Jumlah pengunjung ini murni dari implementasi SEO On page saja. Pengggunaan metode SEO adalah proses yang terbaik dalam menarik pengguna dan untuk mendapatkan lalu lintas akses ke situs web. Hal tersebut karena SEO berguna dalam meningkatkan posisi di hasil pencarian mesin pencari. Teknik-teknik yang berbeda dari SEO On page dan Off Page membantu situs web untuk membuat situs dapat muncul di hasil mesin pencari jika semua teknik ini diterapkan dengan benar [6].

Dari penjelasan yang sudah dipaparkan, SEO On page dan Off page perlu diimplementasikan pada website UKM Madura untuk membantu pemilik UKM mempublikasikan dan menjual produknya, sehingga dapat mengembangkan pemasarannya yang berakibat pada peningkatan nilai produksi dan hasil penjualan produk. Selain itu website perlu untuk dapat dikenali oleh mesin pencari guna mendapatkan pengunjung. Untuk metode optimisasi mesin pencari atau SEO (Search Engine Optimization) On page dan Off page menggunakan panduan resmi dari Google.

\section{DASAR TEORI}

Search engine bisa diartikan program komputer yang dirancang untuk membantu seseorang menemukan informasi atau menemukan berkas yang disimpan komputer baik server umum di world wide web (WWW) atau pada stand alone computer [7]. Search engine merupakan mesin pencari website yang dirancang dengan beberapa konfigurasi yang berbeda-beda, dimana ia harus bisa menangkap banyak terabyte data, kemudian memberikan respon yang cepat untuk jutaan pertanyaan yang diajukan setiap hari dari seluruh dunia [8].

SERP adalah kependekan dari Search Engine Result Page, yaitu halaman hasil penelusuran kata kunci di mesin pencari. Pada intinya Pengertian SERP ini yaitu hasil dari search engine yang menampilkan berjuta website yang memiliki keyword terkait yang dicari berdasarkan urutan kemunculan pada lembar hasil.

\subsection{SEO (Search Engine Optimization)}

SEO merupakan sebuah cara dalam meningkatkan visibilitas sebuah laman website secara alami [8]. Dengan arti lain SEO merupakan serangkaian proses yang dilakukan secara sistematis yang bertujuan untuk meningkatkan kualitas trafik kunjungan melalui mesin pencari menuju situs website tertentu. SEO adalah teknik yang digunakan untuk mendapatkan posisi yang menguntungkan di mesin pencari yang sesuai dengan kata kunci yang berada di halaman website. Adapun optimasi mesin pencari dibagi menjadi dua yaitu SEO On page dan Off page. SEO On page merupakan langkah awal yang harus dilakukan oleh pengembang website. Teknik ini berhubungan dengan perubahan yang dilakukan dalam halaman untuk meningkatkan visibilitas dan peringkat pada hasil mesin pencari. Dengan kata lain optimasi on page merupakan teknik untuk mendapatkan peringkat yang bagus dalam hasil mesin pencari dan meningkatkan 
kepuasan pengunjung. Teknik on page yang dilakukan yaitu memodifikasi Judul, Body text, Hyperlinks, URL, frekuensi kata kunci, robots.txt, sitemaps serta optimasi gambar [8]. Optimasi SEO off page merupakan pelengkap dari optimasi on page. Optimasi ini pada umumnya berkonsentrasi di pembuatan backlink dan pemasaran melalui social media [9]. Dengan kata lain SEO Off Page Optimization merupakan langkah optimasi SEO terhadap suatu website yang dilakukan diluar halaman website tersebut. Optimasi ini meliputi pendaftaran ke mesin pencari, social network sharing, blogwalking, ping dan social bookmarking.

\section{METODOLOGI PENELITIAN}

Penerapan Metode SEO akan dilakukan pada website e-commerce atau penjualan online. Fitur-fitur yang disediakan untuk menunjang penerapan SEO yakni promoting, blogging dan chatting. Fitur-fitur tersebut akan diterapkan metode SEO yang diharapkan dapat membantu website dalam meningkatkan pengunjung organik.

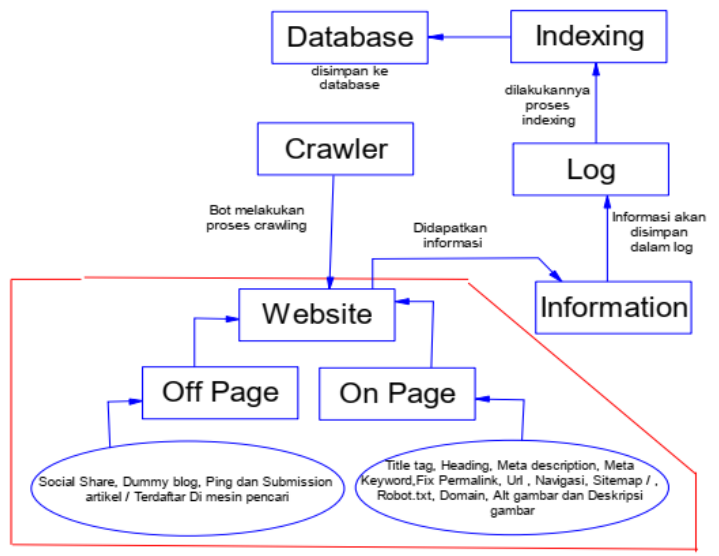

Gambar 1. Struktur Rancangan

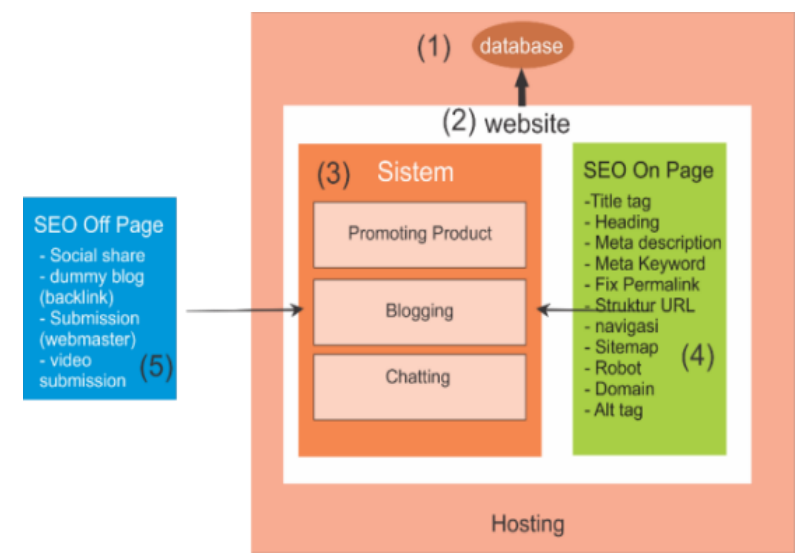

Gambar 2. Arsitektur Website website

Gambar 1 Menjelaskan bagaimana sebuah website dikumpulkan oleh bot dan mengambil setiap informasi yang ada pada website hingga ter-index di database mesin pencarian. Crawler adalah suatu program yang dengan metode tertentu melakukan pelacakan atau "crawl" ke semua halaman-halaman Internet untuk membuat index dari data yang dicarinya. Web crawl dapat digunakan untuk beragam tujuan. Penggunaan yang paling umum adalah mengumpulkan data, sehingga ketika pengguna Internet melakukan pencarian dengan kata kunci tertentu, maka mesin pencari dapat dengan segera menampilkan situs web / blog yang relevan. Gambar 2 merupakan arsitektur sistem website yang mengimplementasikan SEO On page dan SEO Off Page. Adapun, penjelasannya adalah sebagai berikut:

1. Hosting digunakan untuk menampung data-data yang diperlukan oleh sebuah website sehingga dapat diakses melalui internet. Data tersebut berupa berkas, gambar, email, program, script dan database.

2. Website merupakan halaman informasi yang disediakan melalui jalur internet sehingga bisa diakses diseluruh dunia. Dalam website ini dilakukan teknik optimasi yang diperlukan.

3. Sistem yang dikembangkan dalam website ini yaitu:

3.1. Promoting product berfungsi sebagai alat untuk menawarkan produk dengan tujuan menarik calon konsumen untuk membeli produk tertentu.

3.2. Blogging memungkinkan pengguna yang terdaftar dapat memberikan tulisan atau artikel yang bertujuan untuk promosi atau memberikan informasi penting terkait hal tertentu.

3.3. Chatting adalah sebuah fitur yang dikembangkan agar pengguna yang terdaftar dapat melakukan chatting atau berkomunikasi secara langsung ke sesama pengguna website.

4. Metode SEO On Page, metode ini merupakan teknik optimasi yang dilakukan didalam website dimana teknik yang dilakukan meliputi title tag, heading, meta description, meta keyword, 
Keyword pada deskripsi konten / posting, fix permalink, struktur url, navigasi, sitemap, robot, domain, alt tag, dan Deksripsi gambar.

5. Metode SEO Off Page, metode ini merupakan Teknik optimasi yang dilakukan dari luar website. Seperti Social share, submission webmaster, penggunaan dummy blog dan video submission untuk menambah backlink.

\section{HASIL DAN PEMBAHASAN}

SEO merupakan proses atau teknik yang akan terus berlanjut dan website membutuhkan manajemen. SEO yang baik dan perawatan yang terus berlanjut untuk mencegah turunnya peringkat website pada SERP. Gambar 3 yang mengilustrasikan alur flowchart pengujian SEO

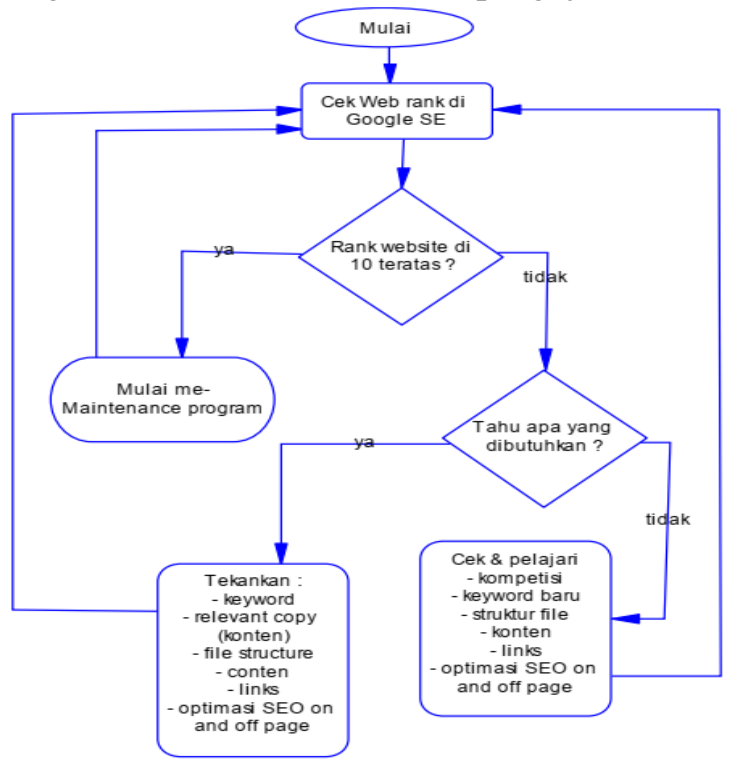

Gambar 3. Diagram Alur pengujian $S E O$

Tabel 1. Pengukuran dan pemantauan hasil

\begin{tabular}{|l|l|l|}
\hline No & \multicolumn{1}{|c|}{$\begin{array}{c}\text { Teknik pengukuran \& } \\
\text { pemantauan }\end{array}$} & \multicolumn{1}{c|}{ Penjelasan } \\
\hline 1 & Pencarian secara manual & $\begin{array}{l}\text { Proses ini dilakukan dengan memasukkan beberapa kata kunci terkait dari } \\
\text { website yang telah di tentukan sebelumnya. }\end{array}$ \\
\hline 2 & Google Webmaster & $\begin{array}{l}\text { Alat ini membantu pemilik website dalam memantau lalu lintas situs web, } \\
\text { mengoptimalkan peringkat situs dan membuat keputusan berdasarkan } \\
\text { informasi yang didapat. }\end{array}$ \\
\hline 3 & Google analytic & $\begin{array}{l}\text { Alat ini merupakan layanan Google yang dapat menampilkan jumlah } \\
\text { pengunjung dari sebuah situs web. }\end{array}$ \\
\hline 4 & Google PageSpeed Insight & $\begin{array}{l}\text { Alat ini digunakan untuk mengetahui tingkat kecepatan loading suatu } \\
\text { website. Hal ini dapat memberikan pengetahuan bagi pemilik website untuk } \\
\text { dapat mengevaluasi terhadap konten yang ditampilkan. }\end{array}$ \\
\hline 5 & MOZ & $\begin{array}{l}\text { MOZ merupakan alat yang dilakukan untuk melakukan riset tentang } \\
\text { optimasi website. }\end{array}$ \\
\hline 6 & $\begin{array}{l}\text { Screaming Frog SEO Spider } \\
\text { tool }\end{array}$ & $\begin{array}{l}\text { Alat ini berguna untuk menjelajah suatu link website mulai dari gambar, } \\
\text { script dll dari perspektif SEO. }\end{array}$ \\
\hline
\end{tabular}

Adapun rancangan metode SEO yang akan dilakukan akan diukur dengan menggunakan pendekatan seperti pada tabel 1. Berikut akan dijelaskan penempatan dan penjelasan kode yang dipasang dalam halaman awal (beranda). 


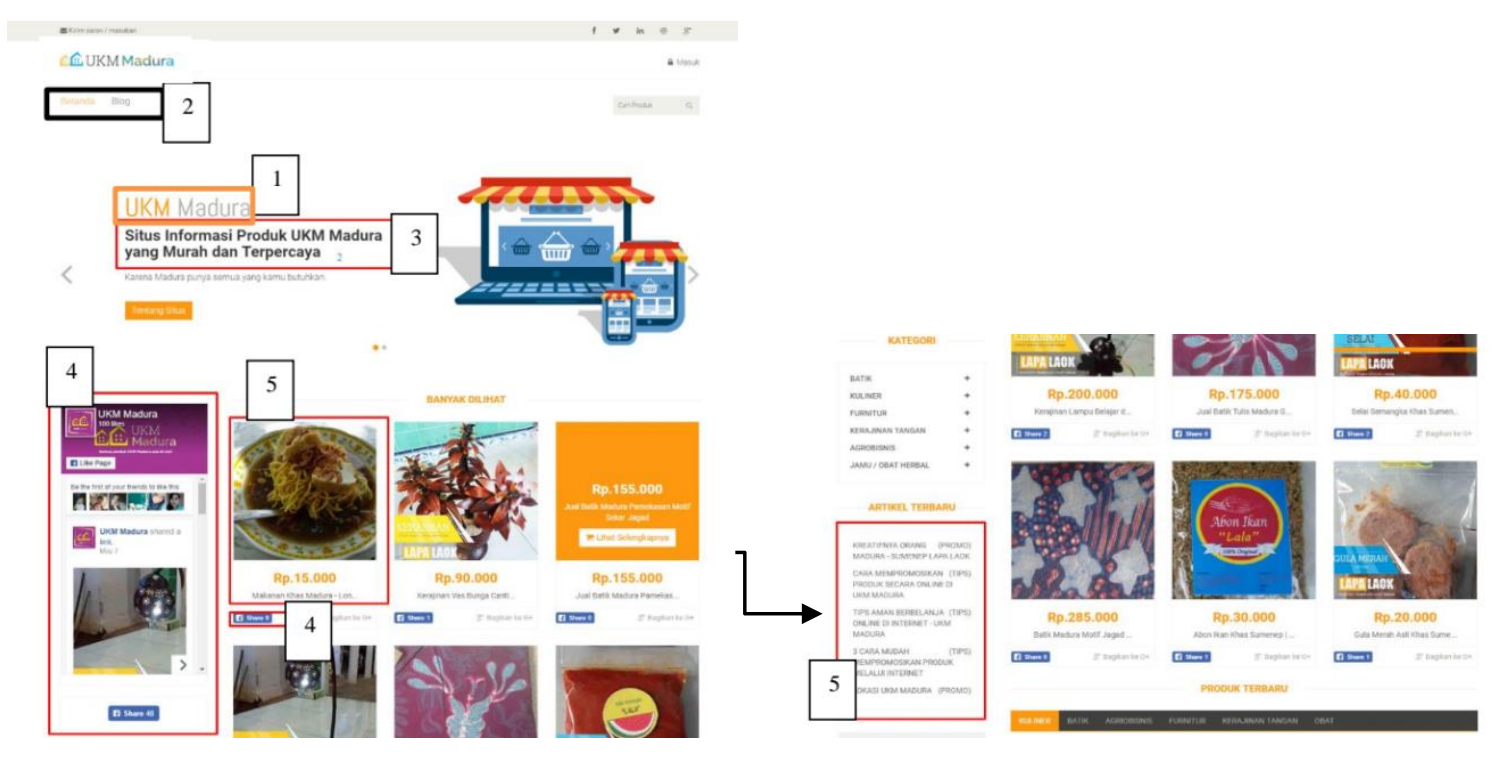

Gambar 3. Penerapan SEO Pada Halaman Awal

Penjelasan pengimplementasian metode SEO pada gambar 3 adalah sebagai berikut:

1. Heading h1, Title tag \& Meta tag. Title tag dari halaman awal ini adalah "UKM Madura". Title akan secara otomatis dihasilkan mengikuti halaman yang dibuka seperti pada gambar 4 .

$$
\sqrt{c \text { Situs Infor } \times<}<\mathrm{h} 1><\text { span }>\mathrm{UKM}</ \text { span }>\text { Madura }</ \mathrm{h} 1>
$$

Gambar 4. Heading h1, Title tag \& Meta tag

2. Navigasi seperti pada gambar 3 terletak pada sidebar dan header.

3. Description merupakan kode deskripsi situs pada halaman index dengan heading $\mathrm{h} 2$ dengan kode HTML seperti pada gambar 5 .

$$
\text { <h2>Situs Informasi Produk UKM Madura yang Murah dan Terpercaya</h2> }
$$

Gambar 5. Kode untuk menampilkan format tulisan ukuran $H 2$

4. Social share merupakan kode untuk membagikan alamat website ke social media. Dan hal ini merupakan salah satu metode SEO Off Page seperti pada gambar 6.

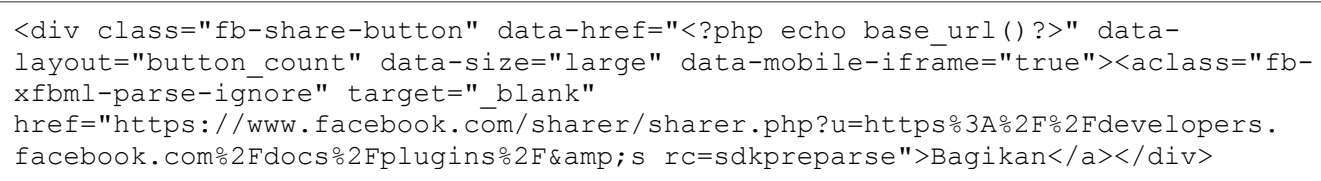

\section{Gambar 6. Kode Social share}

5. Link seperti pada Gambar 7 merupakan kode yang berfungsi sebgai fix permalink. Dimana dalam suatu laman terdapat link untuk menuju ke halaman lainnya dalam website tertentu. Dalam halaman awal ini terdapat beberapa bagian permalink yaitu link untuk mengarahkan pada artikel, produk, dll.

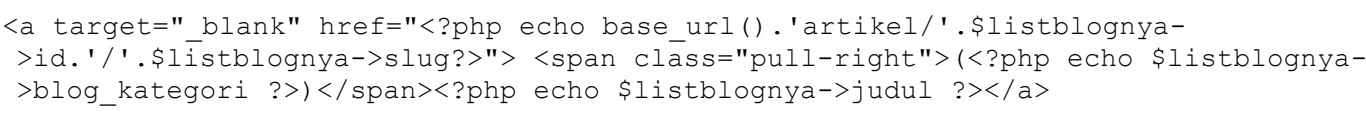

\section{Gambar 7. Kode Link}




\subsection{Pengujian Tanpa SEO}

Pengujian ini dilakukan untuk mengetahui seberapa besar pengaruh metode SEO on Page dan off Page yang telah diimplementasikan kedalam website. Durasi pengujian dilakukan setelah sistem atau website dipublikasikan, dengan masa pengujian selama 3 bulan dimulai pada bulan februari 2017 hingga april 2017. Pengujian pertama dimulai pada tanggal 1 februari hingga 28 februari. Pada tahap ini website yang sudah dipublikasikan tidak menerapkan teknik SEO secara utuh. SEO on page diterapkan hanya beberapa saja karena pada dasarnya teknik On page yang berupa tag h1, tag gambar dan lain sebagainya akan tetap ada didalam website sebagai tag HTML. Berikut akan ditampilkan hasil dari pengujian pertama dengan melihat rank SERP untuk kata kunci yang dicari.

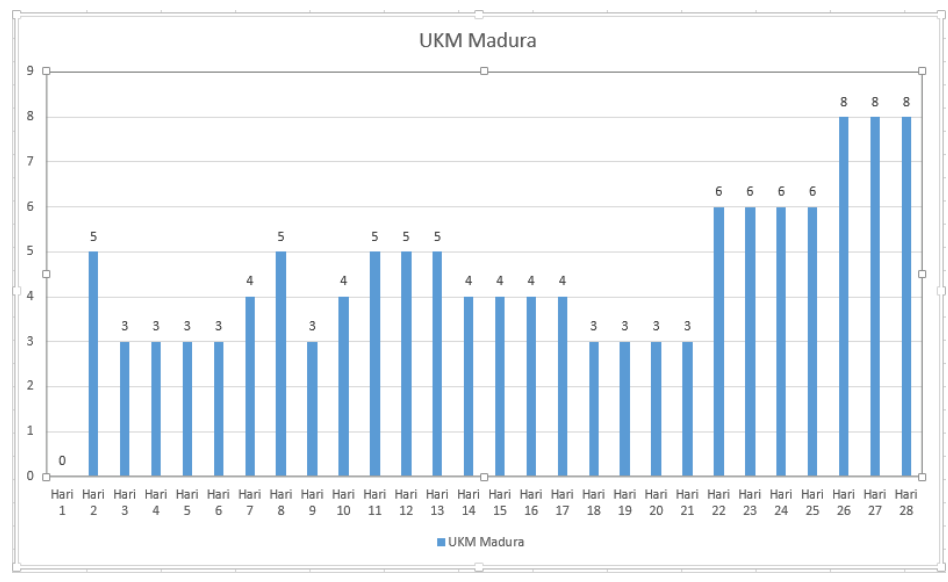

Gambar 8. Hasil Rank Keyword - “UKM Madura” Pada Pengujian 1

Gambar 8 merupakan hasil ranking pencarian search engine Google dengan kata kunci "UKM Madura". Setelah di publish pada hari ke 2 dan dilakukan pencarian, situs website berada pada rank ke 5 kemudian naik hingga rank 3 hingga mengalami fluktuasi dari hari 1 ke hingga ke 10. Pada hari selanjutnya rank mengalami plateu yaitu rank yang tetap dalam beberapa hari kemudian naik dan turun kembali dengan rentang waktu tertentu. Dan itu terjadi hingga hari ke 28.

\subsection{Pengujian dengan SEO}

Pada proses ini seluruh proses SEO akan dilakukan mulai On page dan Off page setelah melewati masa pengujian pertama. Berikut akan ditampilkan hasil dari pengujian pertama dengan melihat rank SERP untuk kata kunci yang dicari. Gambar 9 merupakan hasil ranking pencarian mesin pencarian Google dengan kata Kunci "UKM Madura". Dari hari awal hingga terakhir mengalami peningkatan mulai dari urutan 8 hingga 1. Dari hari ke 59 sampai hari terakhir menunjukkan bahwa dengan kata kunci yang sama posisi peringkat website berada pada urutan 1. Hal ini menunjukkan bahwa penerapan metode SEO pada website sudah menunjukkan hasilnya.

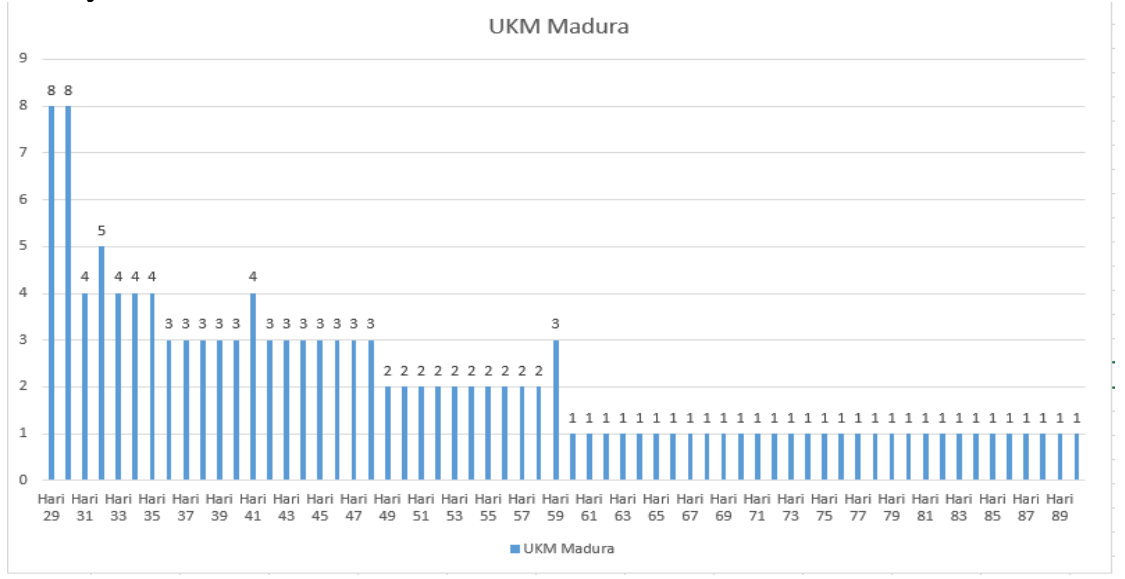

Gambar 9. Hasil Rank Keyword - “UKM Madura” Pada Pengujian kedua 


\subsection{Hasil Perbandingan Pengujian}

Pada gambar 10 ditampilkan grafik yang menunjukkan perbandingan pertama dan kedua (februari dan maret-april) dari lalu lintas langsung, lalu lintas organik, pengguna baru dan pengguna yang kembali yang didapatkan dari Google Analytic. Sumbu y menunjukkan banyaknya pengunjung sedangkan x menunjukkan hari.

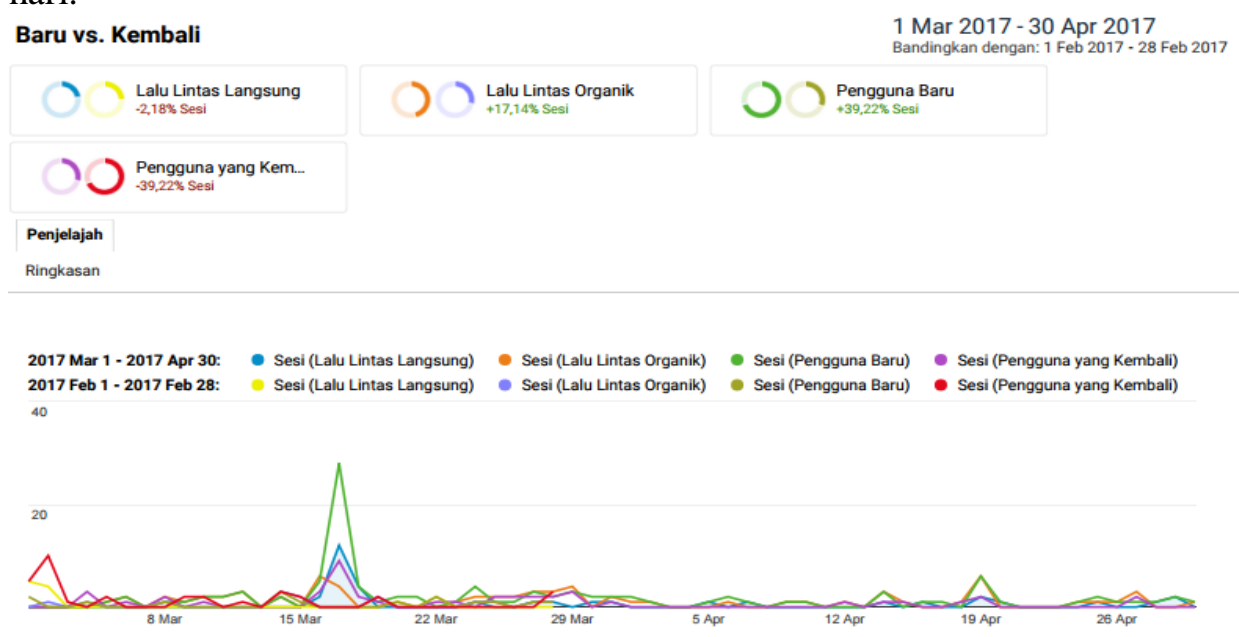

Gambar 10. Grafik Perbandingan Pengujian pertama \& kedua

Tabel 2 merupakan detail rangkuman dari penelitian perbandingan bulan februari dengan maret-april.

Tabel 2. Detail hasil perbandingan Pengujian pertama \& kedua

\begin{tabular}{|l|l|l|}
\hline Channel Saluran & Sesi & Pengguna Baru \\
\hline Semua Pengguna & $210,42 \% 149$ dari 48 (naik) & $600,00 \% 105$ dari 15 \\
\hline Pengguna Baru & $600,00 \%$ 105 dari 15 (naik) & $600,00 \% 105$ dari 15 \\
\hline Pengguna yang Kembali & $33,33 \% 44$ dari 33 (naik) & $0,00 \%$ \\
\hline 6. Organic Search & & \\
\hline 2017 Mar 1 - 2017 Apr 30 & & \\
\hline Semua Pengguna & $69(46,31 \%)$ & $47(44,76 \%)$ \\
\hline Pengguna yang Kembali & $22(50,00 \%)$ & $0,00 \%$ \\
\hline Pengguna Baru & $47(44,76 \%)$ & $47(44,76 \%)$ \\
\hline 2017 Feb 1 - 2017 Feb 28 & & \\
\hline Semua Pengguna & $14(29,17 \%)$ & $10(66,67 \%)$ \\
\hline Pengguna yang Kembali & $4(12,12 \%)$ & $0,00 \%$ \\
\hline Pengguna Baru & $10(66,67 \%)$ & $10(66,67 \%)$ \\
\hline 7. Social & & \\
\hline 2017 Mar 1 - 2017 Apr 30 & & \\
\hline Semua Pengguna & $40(26,85 \%)$ & $20(19,05 \%)$ \\
\hline Pengguna yang Kembali & $20(45,45 \%)$ & $0,00 \%$ \\
\hline Pengguna Baru & $20(19,05 \%)$ & $20(19,05 \%)$ \\
\hline 2017 Feb 1 - 2017 Feb 28 & & \\
\hline Semua Pengguna & $19(39,58 \%)$ & $0(0,00 \%)$ \\
\hline Pengguna yang Kembali & $19(57,58 \%)$ & $0(0,00 \%)$ \\
\hline Pengguna Baru & $0(0,00 \%)$ & $0(0,00 \%)$ \\
\hline 8. Direct & & \\
\hline 2017 Mar 1 - 2017 Apr 30 & & $34(22,82 \%)$ \\
\hline Semua Pengguna & $34(22,82 \%)$ & $0(0,00 \%)$ \\
\hline Pengguna yang Kembali & $0(0,00 \%)$ & $34(32,38 \%)$ \\
\hline Pengguna Baru & $34(32,38 \%)$ & \\
\hline 2017 Feb 1 - 2017 Feb 28 & & \\
\hline & & \\
\hline
\end{tabular}




\begin{tabular}{|l|l|l|}
\hline Semua Pengguna & $12(25,00 \%)$ & $5(33,33 \%)$ \\
\hline Pengguna yang Kembali & $7(21,21 \%)$ & $0(0,00 \%)$ \\
\hline Pengguna Baru & $5(33,33 \%)$ & $5(33,33 \%)$ \\
\hline 9. Referral & & \\
\hline 2017 Mar 1 - 2017 Apr 30 & & \\
\hline Semua Pengguna & $6(4,03 \%)$ & $4(3,81 \%)$ \\
\hline Pengguna yang Kembali & $2(4,55 \%)$ & $0(0,00 \%)$ \\
\hline Pengguna Baru & $4(3,81 \%)$ & $4(3,81 \%)$ \\
\hline 2017 Feb 1 - 2017 Feb 28 & & \\
\hline Semua Pengguna & $3(6,25 \%)$ & $0(0,00 \%)$ \\
\hline Pengguna yang Kembali & $3(9,09 \%)$ & $0(0,00 \%)$ \\
\hline Pengguna Baru & $0(0,00 \%)$ & $0(0,00 \%)$ \\
\hline
\end{tabular}

Dari tabel 2 dapat dilihat bahwa perbandingan antara bulan februari dan maret-april terjadi kenaikan. Total seluruh sesi pada pengujian kedua yaitu sebanyak 149 dan pengujian pertama yang hanya sebanyak 48 dimana persentase kenaikan sesi yaitu 210,42\%. Pengguna baru mengalami kenaikan hingga 600,00\%, dari 15 pada pengujian pertama hingga 105 pada pengujian kedua. Sedangkan pengguna yang kembali naik hingga 33,33\% dimana pada pengujian kedua sebanyak 44 dan pertama hanya sebesar 33. Kesimpulan dari tabel 10 ini adalah bahwa telah terjadi peningkatan pengunjung dari pengujian pertama hingga pengujian kedua.

\section{KESIMPULAN}

Dari data hasil pengujian tentang pengimplementasian metode SEO terhadap website penjualan online menunjukan adanya peningkatan ranking pada SERP dan pengguna. Dilihat dari hasil pengujian, pengguna baru yang didapatkan sebesar 105, lebih besar daripada pengujian pertama yang hanya mendapatkan 15 pengguna baru (kenaikan mencapai 600\%). Sedangkan keseluruhan sesi yang didapatkan adalah 149 pada pengujian ke 2 dan 48 pada pengujian ke 1 (kenaikan mencapai 210,42\%). Dilihat dari lalu lintas yang bersumber pada pencarian organik, secara total terdapat 69 pengguna $(46,31 \%)$ dengan pengguna baru sebesar $47(44,67 \%)$ pada pengujian kedua dan lebih besar dibandingkan dengan pengujian pertama yakni terdapat $10(10,66)$ pengguna baru dengan total seluruh pengguna sebanyak $14(29,17 \%)$. Dan jika dilihat dari posisi SERP terdapat peningkatan yang pesat dengan rata-rata kemunculan website berada pada halaman 1 jika dibandingkan dengan pengujian website tanpa menggunakan metode SEO yang rata-rata kemunculan website berada pada rank 6 untuk kata kunci "UKM Madura". Peningkatan rank juga terjadi pada seluruh keyword yang diuji. Sehingga dapat disimpulkan bahwa penggunaan metode SEO dengan benar dapat mempengaruhi popularitas sebuah website dalam posisi SERP.

\section{DAFTAR PUSTAKA}

[1] M. F. Toisuta, "Peran E-commerce Untuk Meningkatkan Daya Saing UKM," p. 9, 2010.

[2] K. Hernawati, "Optimalisasi SEO (Search Engine Optimizer) sebagai upaya meningkatkan unsur Visibility dalam Webometric," 16 Januari 2013.

[3] A. Jain, "The Role and Importance of Search Engine and Search Engine Optimization," International Journal of Emerging Trends \& Technology in Computer Science, vol. 2, no. 3, p. 99, May - June 2013.

[4] M. Usha dan D. N. Nagadeepa, "On-Page and Off-Page Optimization Techniques for Search Engine Results Page (SERP)," International Journal of Advanced Research in Computer Science and Software Engineering, vol. 5, no. 1, p. 1042, January 2015.

[5] R. B. Lukito, C. Lukito and D. Arifin, "Penerapan Teknik SEO (Search Engine Optimization) Pada Website Dalam Strategi Pemasaran Melalui Internet," ComTech, vol. Vol. 5 No. 2, p. 1057, 2 Desember 2014.

[6] J. S. Poongkode and V.Nirosha, "A Study on Various Search Engine Optimization Techniques," International Journal of Innovative Research in Computer and Communication Engineering, vol. 2, no. 11, p. 6742, November 2014.

[7] L. and L. Jerri, Search Engine Optimization Bible, Inc. Indiana: Wiley Publishing, 2007, p. 411. 
[8] W. B. Croft, D. Metzler and T. Strohman, "Search Engines," in Information Retrieval in Practice, Pearson Education, Inc., 2015, p. 7.

[9] V. K. Gunjan, P. M. Kumari, A. Kumar and A. A. Rao, "Search engine optimization with Google," IJCSI International Journal of Computer Science Issues, vol. Vol. 9, p. 206, 3 January 2012. 